\title{
Human papillomavirus prevalence in women with normal cytology and with cervical cancer in Natal, Brazil
}

\author{
JOSÉ VERÍSSIMO FERNANDES ${ }^{1}$, ROSELY DE VASCONCELLOS MEISSNER ${ }^{1}$, \\ MARIA GORETTI FREIRE CARVALHO ${ }^{2}$, THALES ALLYRIO ARAÚJO DE MEDEIROS FERNANDES ${ }^{3}$, \\ PAULO ROBERTO MEDEIROS AZEVEDO ${ }^{4}$, JUDSON WEBER VERÍSSIMO DE AZEVEDO ${ }^{1}$ \\ and JOSÉLIO MARIA GALVÃO DE ARAÚJO ${ }^{1}$
}

\begin{abstract}
${ }^{1}$ Department of Microbiology and Parasitology, Federal University of Rio Grande do Norte, Campus Universitário, Lagoa Nova, Natal; ${ }^{2}$ Department of Pathology, Federal University of Rio Grande do Norte, Petrópolis, Natal; ${ }^{3}$ Department of Biomedical Sciences, University of Rio Grande do Norte State, Mossoró; ${ }^{4}$ Department of Statistics, Federal University of Rio Grande do Norte, Campus Universitário, Lagoa Nova, Natal, Brazil
\end{abstract}

Received May 13, 2011; Accepted August 19, 2011

DOI: $10.3892 / \mathrm{mmr} .2011 .579$

\begin{abstract}
This study analyzed the prevalence of human papillomavirus (HPV) in cervical specimens obtained from women with normal cytology and with cervical cancer, in order to evaluate their correlation with health status and demographic characteristics, as well as sexual and reproductive activity in women treated at a cancer reference hospital in Natal, Northeast Brazil. A total of 158 women were divided into 2 groups according to their health status: group I comprised 110 women with normal cytology, and group II comprised 48 women with cervical cancer. Cervical smears were analyzed by cytological or histopathological examination for the detection of cytological alterations, and by PCR for HPV DNA detection using MY09/11 primers, followed by HPV genotyping by dot blot hybridization. Results showed overall HPV prevalence to be $24.5 \%$ in group I, with $19.1 \%$ of patients having single infection and $5.4 \%$ double infection. The HPV prevalence in group II was $85.4 \%$, with $79.2 \%$ of patients having single and $6.2 \%$ double infection. We identified 10 different HPV genotypes, most with high oncogenic potential. HPV 16 was the most prevalent genotype in the two studied groups, followed by HPV 58 and HPV 18. High-risk HPV genital infection, chronological age, ethnicity, early onset of sexual and reproductive activities, multiple sexual partners and smoking increased the risk for cervical cancer.
\end{abstract}

Correspondence to: Professor José Veríssimo Fernandes, Departamento de Microbiologia e Parasitologia, Centro de Biociências, Universidade Federal do Rio Grande do Norte, Av. Sen. Salgado Filho, S/N, Campus Universitário, Lagoa Nova, Natal, RN CEP: 59072-970, Brazil

E-mail: veris@cb.ufrn.br

Key words: human papillomavirus, uterine cervical cancer, risk factors

\section{Introduction}

Human papillomavirus (HPV) is among the most common causes of sexually transmitted infection in women worldwide, particularly in developing countries, where the most sexually active individuals are likely to be exposed to these viruses during their lifetime (1-3). Most HPV infections clear spontaneously, but some persist. Persistent infection by certain HPV genotypes, designated as high-risk HPV, may progress to malignant lesions. These types of viruses were identified as a necessary cause, although they are not sufficient, for the development of cervical cancer $(3,4)$.

Genital HPV infection is a common event among sexually active women, particularly younger women, with the highest prevalence occurring up to 30 years of age, followed by a decline until age 45-50 and a second peak of incidence observed in the peri- or post-menopausal period (5-7). Most of the infections appear to be transitory and with little clinical significance (8). However, some of women with persistent highrisk HPV infection, especially with non-European HPV 16 variants, present a greater risk of progression to high-grade cervical lesions, particularly the infections with a high viral load $(9,10)$. Tumor progression is a complex phenomenon that depends on multiple factors, including the type and variant of the virus, the combination of environmental factors, the host itself, genetic background and immune status, as well as sexual, behavioral and reproductive activities $(10,11)$.

The present study evaluated the prevalence of HPV DNA in women with normal cytology and with cervical cancer treated in a cancer reference hospital in northeastern Brazil. The prevalence of the viral genotypes, as well as their association with socio-demographic characteristics, sexual and reproductive behavior and smoking habits of the participants were also analyzed.

\section{Materials and methods}

We analyzed cervical specimens of 112 women enrolled in the cervical cancer screening program of Luis Antonio Hospital, 
a cancer reference hospital in Natal, Rio Grande do Norte State, and 48 women with suspected cervical cancer who were referred to the same hospital, between April 2001 and June 2002. Two specimens containing exfoliated cells of the uterine cervix were collected from the women attending the cancer-screening program using a cervical brush. One of these specimens was used for the Pap smear examination, based on the Bethesda system (12). The smears were analyzed by a trained pathologist from the Department of Pathology at the Federal University of Rio Grande do Norte. The other specimen was collected, placed in a tube containing a preserving solution [phosphate-buffered saline (PBS) combined with $0.25 \mathrm{U} / \mathrm{ml}$ of vancomicine + nistatine], and sent to a laboratory where it was processed for DNA extraction and analyzed for HPV detection and typing. Two samples of exfoliated cells with scant squamous cellularity were considered unsatisfactory for evaluation and were excluded from analysis.

A fragment of tissue was obtained by biopsy from women referred to the hospital with suspected cervical cancer. The fragment was analyzed through histopathological examination. Subsequently, another fragment of tissue was obtained from women with a diagnosis of cervical cancer at surgery following the conization procedure. The fragment was obtained and re-examined for result confirmation. In this study, 110 women were selected from those who had spontaneously used the cancer-screening program for a periodical Pap smear and who presented no cytological alterations, and 48 women were selected among those who had been referred to the service with suspected cervical cancer and who had confirmed diagnosis.

All women were informed about the methods and objectives of the study and informed consent was obtained. A standardized questionnaire, administered to the participants by a trained interviewer, included questions about socio-demographic characteristics, sexual and reproductive behavior and smoking habits. Patient ethnicity was defined based on selfreports according to the criterion of the Instituto Brasileiro de Geografia e Estatística (IBGE) that classifies ethnicity into five categories: Caucasian, of African descent, mulatto, of Asian descent and native. In this study, the ethnicity groups including those of African descent, mulatto, of Asian descent and native categories were combined into a non-Caucasian category.

DNA extraction. The tubes containing the cervical specimens underwent vigorous agitation prior to removal of the brush and were centrifuged at $3000 \mathrm{x}$ g for $10 \mathrm{~min}$. The supernatant was removed and the resulting pellet was processed for DNA extraction, using rapid isolation of DNA from mammals, with proteinase K (12). Small fragments of tissues obtained by biopsy or collected at the surgical procedure were incubated in $200 \mu \mathrm{l}$ of digestion buffer (0.01 M Tris-HCl, 0.02 M EDTA, $0.1 \mathrm{M} \mathrm{NaCl}, 0.5 \% \mathrm{SDS}, \mathrm{pH} 8.0)$ and $20 \mu \mathrm{l}$ proteinase $\mathrm{K} 10 \mathrm{mg} /$ $\mathrm{ml}$ at $42^{\circ} \mathrm{C}$ overnight, $56^{\circ} \mathrm{C}$ for $3 \mathrm{~h}$ and at $95^{\circ} \mathrm{C}$ for $5 \mathrm{~min}$. DNA extraction was performed using the phenol/chloroform method (13).

HPV DNA detection and typing. To analyze the quality of target DNA, DNA samples were quantified by $0.8 \%$ agarose gel electrophoresis, and aliquots with approximately $30 \mathrm{ng}$ of DNA underwent polymerase chain reaction (PCR) using
PCO3/PCO4 primers, as described by Saiki et al (14), specific for the amplification of $110 \mathrm{bp}$ of the $\beta$-globin gene. All $\beta$-globin-positive samples were included in this study. Samples from 158 women, 110 with normal cytology (group I) and 48 with cervical cancer (group II), were analyzed by PCR for HPV DNA detection using the consensus primers MY09/M11, specific for the L1 ORF region of HPV as described by Manos et al (15). The products of PCR were electrophoresed on a $7 \%$ polyacrylamide gel, followed by silver staining, according to Sanguinetti et al (16). The amplicons were submitted for genotyping of the individual HPV types by dot blot hybridization using specific radioactive probes for the following types of HPV: 6, 11, 16, 18, 26, 31, 33, 35, 39, 40, 42, 45, 51, 52, 53, 54, $55,56,57,58,59,66,68,70,72$ and 73 , isolated or in cocktails, as described by Jacobs et al (17).

Statistical analysis. To estimate the risk of cervical cancer associated with various HPV types and other risk factors, odds ratios (OR) and 95\% confidence intervals (CIs) were calculated, according to the adjusted univariate and multivariate regression model. Statistical significance within each group was evaluated by Pearson's $\chi^{2}$ test. To perform statistical tests and to calculate the ORs and $95 \%$ CIs, we used the software SPSS, version 17.0. $\mathrm{P} \leq 0.05$ was considered to be statistically significant.

The study protocol was approved by the Ethics Committee of the Universidade Federal do Rio Grande do Norte (CEP-UFRN).

\section{Results}

The distribution of the women enrolled in this study according to socio-demographic reproductive and behavioral characteristics showed that the age ranged from 15 to 65 years old, with a mean age of $29.4( \pm 9.609$ years) for the women in group I and 47.3 ( \pm 9.109 years) in group II. Distribution by age group showed that the majority of the women in group I $(55.5 \%)$ were up to 30 years old, of Caucasian ethnicity, married or in a stable relationship with their partner, non-smokers and had only one sexual lifetime partner. The majority of the women from group II $(70.8 \%)$ were above 40 years old, of nonCaucasian ethnicity, married or in a stable relationship with their partner, smokers and had more than one sexual lifetime partner. Overall HPV prevalence was $24.5 \%$ for the women in group I, with a higher prevalence rate in those up to 30 years old. In group II, overall HPV prevalence was $85.4 \%$, with rates varying from 76.9 to $100 \%$. The statistical analysis through the $\chi^{2}$ test revealed that the HPV prevalence rate was higher for the women in groups I and II among those who had more than one sexual lifetime partner $(p=0.0000$ and $p=0.0004)$, and among the smokers only in group II $(\mathrm{p}=0.0008)$. No association was observed between age group, ethnicity, or marital status and HPV presence (Table I).

The statistical analysis by logistic regression showed that an HPV infection of high oncogenic potential increased the risk of development of cervical cancer independently of any other variable. We observed a tendency of augmentation of the number of cervical cancer cases proportional to the chronological age, with a higher risk of occurrence of the disease after age 40. Females of non-Caucasian ethnicity, 
Table I. Socio-demographic characteristics and HPV prevalence according to health status.

\begin{tabular}{|c|c|c|c|c|c|c|c|c|}
\hline \multirow[t]{2}{*}{$\begin{array}{l}\text { Demographic } \\
\text { variable }\end{array}$} & \multicolumn{4}{|c|}{$\begin{array}{c}\text { Group I } \\
\text { Normal cytology }\end{array}$} & \multicolumn{4}{|c|}{$\begin{array}{c}\text { Group II } \\
\text { Cervical cancer }\end{array}$} \\
\hline & $\mathrm{n}=110$ & $(\%)$ & HPV (+) & $\mathrm{p}$-value ${ }^{\mathrm{a}}$ & $\mathrm{n}=48$ & $(\%)$ & HPV (+) & $\mathrm{p}$-value $\mathrm{a}^{\mathrm{a}}$ \\
\hline \multicolumn{9}{|l|}{ Age (years) } \\
\hline$\leq 30$ & 61 & 55.5 & 19 & & 1 & 2.1 & 1 & \\
\hline $31-40$ & 37 & 33.6 & 6 & 0.3511 & 13 & 27.1 & 10 & 0.4572 \\
\hline $41-50$ & 5 & 4.5 & 1 & & 19 & 39.6 & 18 & \\
\hline$>51$ & 7 & 6.4 & 1 & & 15 & 31.2 & 12 & \\
\hline \multicolumn{9}{|l|}{ Ethnicity } \\
\hline Caucasian & 87 & 79.1 & 19 & & 19 & 39.6 & 17 & \\
\hline Non-Caucasian & 23 & 20.9 & 8 & 0.1996 & 29 & 60.4 & 24 & 0.5192 \\
\hline \multicolumn{9}{|l|}{ Marital status } \\
\hline Single & 32 & 29.1 & 11 & & 9 & 18.8 & 8 & \\
\hline Married & 78 & 70.9 & 16 & 0.1249 & 39 & 81.2 & 33 & 0.7433 \\
\hline \multicolumn{9}{|l|}{$\begin{array}{l}\text { More than one } \\
\text { sexual partner }\end{array}$} \\
\hline Yes & 29 & 26.4 & 17 & & 34 & 70.8 & 33 & \\
\hline No & 81 & 73.6 & 10 & $0.0000^{\mathrm{b}}$ & 14 & 29.2 & 8 & $0.0004^{\mathrm{b}}$ \\
\hline \multicolumn{9}{|l|}{ Smoking } \\
\hline Yes & 12 & 10.9 & 4 & & 33 & 68.8 & 32 & \\
\hline No & 98 & 89.1 & 23 & 0.4536 & 15 & 31.2 & 9 & $0.0008^{\mathrm{b}}$ \\
\hline
\end{tabular}

HPV, human papillomavirus. ${ }^{\text {a }}$-value of the $\chi^{2}$ test between analyzed variables and HPV prevalence. ${ }^{\mathrm{b}}$ Statistically significant.

who had their first sexual intercourse at age 14-17, who had sexual relationships with more than one partner in their lifetime, and were smokers, presented a higher risk of developing cervical cancer. Those who had their first pregnancy at age 21 or above, presented a lower risk of cervical cancer (Table II).

Ten different HPV types were identified: seven were classified as high-risk or of high oncogenic potential (HPV 16, 18, 33, 45, 56, 58 and 59); one as probably of high-risk, HPV 68; and two with indeterminate risk, HPV 55 and 57. In 2 samples of the women with normal cytology and 1 with cervical cancer, the HPV genotypes could not be identified with the probes used. Overall HPV prevalence in the women with normal cytology was $24.5 \%$ : $19.1 \%$ with single infection and $5.4 \%$ with double infection. Considering single and double HPV infection, HPV 16 was the most prevalent genotype in the women with normal cytology, with a prevalence rate of $15.4 \%$, followed by HPV 58 with $5.4 \%$. The most common association observed in this group was that between HPV $16+58$ and HPV $56+57$, each was detected in $1.8 \%$ of the samples.

In the group with cervical cancer, the overall HPV prevalence was $85.4 \%$, with $79.2 \%$ of the cases with single infection and $6.2 \%$ with the double form of infection. Considering single and double HPV infection, HPV 16 was the most prevalent genotype found in $58.3 \%$ of the patients, followed by HPV 58 with a prevalence rate of $12.5 \%$ and HPV 18 with $8.3 \%$. HPV 33 and 45 were the fourth most frequent genotypes, with prevalence rates of $4.2 \%$ each. The statistical analysis by logistic regression showed that single infection with HPV 16, 18, and
58 as well as double infection by HPV $16+58$, increased the risk of development of cervical cancer (Table III).

\section{Discussion}

The association between cervical cancer and genital infection with high-risk HPV genotypes is clearly demonstrated (7,18-20). The Centers for Disease Control and Prevention (CDC) estimates that at least half of all sexually active individuals are likely to acquire HPV infection at some point in their lives, whereas at least $80 \%$ of women may acquire this pathogen before the age of 50 (21). Genital persistent infection with high-risk HPV has been firmly established biologically and epidemiologically as playing a causal role in all types of cancer of the uterine cervix; however, other cofactors are necessary for progression of the low-grade cervical lesions to cancer $(4,11)$. In this study, we evaluated the role of HPV in cervical cancer, as well as the effect of certain characteristics of the patients with probable risk factors.

The mean age of the patients with cervical cancer was 47.3 years old, similar to that reported in a multicentric study covering countries on four continents $(47.8 \%)$, but above the mean age described for African countries (33.9 years old) (22) and below the means described in São Paulo (southeastern Brazil, 52 years old), Belém (northern Brazil, 51 years old), and Goiânia (Central Brazil, 49 years old) $(1,23,24)$. The mean age found in this study was also below the mean age reported in a multicentric study covering 9 developing countries, including Brazil, whose mean age was 49 years (25). These results suggest 
Table II. OR for the association between selected variables and health status of the patients.

\begin{tabular}{|c|c|c|c|c|c|c|}
\hline \multirow{3}{*}{ Variable } & \multicolumn{2}{|c|}{ Health status } & \multicolumn{4}{|c|}{ Logistic regression model } \\
\hline & \multirow{2}{*}{$\begin{array}{l}\text { Normal } \\
n=110\end{array}$} & \multirow{2}{*}{$\frac{\text { Cancer }}{\mathrm{n}=48}$} & \multicolumn{2}{|c|}{ Univariate } & \multicolumn{2}{|c|}{ Multiple } \\
\hline & & & OR & $(95 \% \mathrm{CI})$ & OR & $(95 \% \mathrm{CI})$ \\
\hline \multicolumn{7}{|l|}{ HPV presence } \\
\hline Yes & 27 & 41 & 18.00 & $(7.24-44.80)^{\mathrm{a}}$ & 9.97 & $(1.61-61.92)^{\mathrm{a}}$ \\
\hline No & 83 & 7 & 1.00 & (Refs.) & 1.00 & (Refs.) \\
\hline \multicolumn{7}{|l|}{ Age (years) } \\
\hline$\leq 30$ & 61 & 1 & 1.00 & (Refs.) & 1.00 & (Refs.) \\
\hline $31-40$ & 37 & 13 & 21.43 & $(2.69-170.62)^{\mathrm{a}}$ & 4.78 & $(0.94-24.31)$ \\
\hline $41-50$ & 5 & 19 & 231.80 & $(25.48-2108.63)^{\mathrm{a}}$ & 35.66 & $(5.68-223.95)^{\mathrm{a}}$ \\
\hline$\geq 51$ & 7 & 15 & 130.71 & $(14.92-1194.44)^{\mathrm{a}}$ & 40.42 & $(5.69-287.44)^{\mathrm{a}}$ \\
\hline \multicolumn{7}{|l|}{ Ethnicity } \\
\hline Caucasian & 87 & 19 & 1.00 & (Refs.) & 1.00 & (Refs.) \\
\hline Non-Caucasian & 23 & 29 & 5.77 & $(2.76-12.09)^{\mathrm{a}}$ & 5.06 & $(1.54-16.63)^{\mathrm{a}}$ \\
\hline \multicolumn{7}{|l|}{ Marital status } \\
\hline Married & 78 & 39 & 1.78 & $(0.77-4.09)$ & 0.77 & $(0.21-2.79)$ \\
\hline Single & 32 & 9 & 1.00 & (Refs.) & 1.00 & (Refs.) \\
\hline \multicolumn{7}{|c|}{ Age at first sexual intercourse } \\
\hline $14-17$ & 40 & 39 & 6.83 & $(1.46-32.02)^{\mathrm{a}}$ & 0.09 & $(0.01-0.82)^{\mathrm{a}}$ \\
\hline $18-21$ & 56 & 7 & 0.88 & $(0.16-4.68)$ & 0.02 & $(0.00-0.26)^{\mathrm{a}}$ \\
\hline$>21$ & 14 & 2 & 1.00 & (Refs.) & 1.00 & (Refs.) \\
\hline \multicolumn{7}{|c|}{ Age at first pregnancy } \\
\hline Never pregnant & 15 & 0 & 1.00 & (Refs.) & 1.00 & (Refs.) \\
\hline $14-17$ & 31 & 34 & 1.10 & $(0.67-1.78)$ & 0.16 & $(0.01-1.96)$ \\
\hline $18-21$ & 42 & 10 & 0.24 & $(0.12-0.48)^{\mathrm{a}}$ & 0.29 & $(0.02-3.68)$ \\
\hline$>21$ & 22 & 4 & 0.18 & $(0.06-0.53)^{\mathrm{a}}$ & 0.04 & $(0.00-0.35)^{\mathrm{a}}$ \\
\hline \multicolumn{7}{|c|}{ More than one partner } \\
\hline Yes & 34 & 34 & 5.43 & $(2.58-11.40)^{\mathrm{a}}$ & 0.79 & $(0.17-3.76)$ \\
\hline No & 76 & 14 & 1.00 & (Refs.) & 1.00 & (Refs.) \\
\hline \multicolumn{7}{|l|}{ Smoking } \\
\hline Yes & 18 & 33 & 11.24 & $(5.09-24.83)^{\mathrm{a}}$ & 1.25 & $(0.35-4.53)$ \\
\hline No & 92 & 15 & 1.00 & (Refs.) & 1.00 & (Refs.) \\
\hline
\end{tabular}

OR, odds ratio; 95\% CI, confidence interval. ' Statistically significant.

that HPV infections occur earlier in women from the Northeast region of the country. An indication of this finding is that, among the women in this study with normal cytology infected with HPV, $50 \%$ of them were below 25 years of age.

Among the women with normal cytology, the HPV prevalence was significantly higher only in those who had more than one sexual lifetime partner, while in the women with cervical cancer the difference in HPV rate prevalence was significant for those who had a sexual relationship with more than one partner during their lifetime and for the smokers. In this study, chronological age, ethnicity and marital status did not show an association with augmentation of HPV prevalence rates in groups I or II.

In this study, the presence of HPV, conforming to what was expected and widely described $(4,9-11,23)$, presented a strong association with cervical cancer occurrence, independently of other risk factors. We observed a tendency of an increase in the number of cases of cervical cancer with chronological age, confirming results obtained in São Paulo (23) and in Hong Kong, China (7). The higher number of non-Caucasian women observed among the carriers of cervical cancer is coherent with the results reported by Schoell et al (26) regarding the women in Miami, USA. However, it is probable that this may be more related to the social and economic conditions of the patients than to their ethnic characteristics.

In the present study, initiating sexual and reproductive activity at an early age, a sexual relationship with more than one partner during their lifetime, and smoking, presented an increased risk of cervical cancer, and appeared to be significant risk factors for the disease. These results are coherent, at least in part, with those reported by other investigators $(11,23-24)$. 
Table III. Distribution of the most prevalent HPV types according to health status and associated OR obtained by the univariate logistic regression model.

\begin{tabular}{|c|c|c|c|c|}
\hline \multirow[t]{2}{*}{ HPV infection } & \multirow{2}{*}{$\frac{\text { Normal cytology }(\mathrm{n}=110)}{\text { Patients, no. }(\%)}$} & \multicolumn{3}{|c|}{ Cervical cancer $(n=48)$} \\
\hline & & Patients, no. (\%) & OR & $95 \% \mathrm{CI}$ \\
\hline \multicolumn{5}{|l|}{ Type } \\
\hline HPV 16 & $14(12.7)$ & $25(52.1)$ & 21.17 & $(7.70-58.22)^{\mathrm{a}}$ \\
\hline HPV 18 & $1(0.9)$ & $3(6.3)$ & 35.57 & $(3.26-388.61)^{\mathrm{a}}$ \\
\hline HPV 33 & - & $2(4.2)$ & - & - \\
\hline HPV 45 & - & $2(4.2)$ & - & - \\
\hline HPV 58 & $3(2.7)$ & $4(8.3)$ & 15.81 & $(2.94-85.17)^{\mathrm{a}}$ \\
\hline HPV 59 & $1(0.9)$ & - & - & - \\
\hline HPV 68 & - & $1(2.1)$ & - & - \\
\hline Untyped HPV & $2(1.8)$ & $1(2.1)$ & 5.93 & $(0.48-73.78)$ \\
\hline Sub-total positive samples & $21(19.1)$ & $38(79.2)$ & 21.45 & $(8.40-54.79)^{\mathrm{a}}$ \\
\hline \multicolumn{5}{|l|}{ Double infection } \\
\hline HPV $16+18$ & $1(0.9)$ & $1(2.1)$ & 11.86 & $(0.67-210.63)$ \\
\hline HPV $16+58$ & $2(1.8)$ & $2(4.2)$ & 11.86 & $(1.44-97.44)^{\mathrm{a}}$ \\
\hline HPV $56+57$ & $2(1.8)$ & - & - & - \\
\hline HPV $58+55$ & $1(0.9)$ & - & - & - \\
\hline Sub-total positive double samples & $6(5.4)$ & $3(6.3)$ & 5.93 & $(1.21-29.00)^{\mathrm{a}}$ \\
\hline Total HPV-positive samples & $27(24.5)$ & $41(85.4)$ & 18.00 & $(7.24-44.80)^{\mathrm{a}}$ \\
\hline Total HPV-negative samples & $83(75.5)$ & $7(14.6)$ & 1.0 & (Refs.) \\
\hline
\end{tabular}

OR, odds ratio; 95\% CI, confidence interval; HPV, human papillomavirus. a Statistically significant.

Findings of this study showed the overall HPV infection prevalence to be $24.5 \%$ in women with normal cytology, which is similar to that reported for Sub-Saharan Africa (24.7\%) in a pooled analysis by Clifford et al (27). The prevalence rate found in this study was similar to that reported in the same region (19.5\%) by Lorenzato et al (28) in Recife, and higher compared to the prevalence rate observed in other regions of southeastern (17.0\%) (23) and southern Brazil (16.0\%) (29), in which PCR-based assays using the consensus primer MY09/11 were also used for the detection of viral DNA.

We observed that of the women with normal cytology who were HPV PCR-positive, 92.6\% were infected by at least one high-risk HPV genotype. Considering single infection and association with other genotypes, HPV 16 was the most prevalent genotype detected in $15.4 \%$ of the samples, followed by HPV 58 in $5.4 \%$. The third most common genotypes were HPV 18, 56 and 57, each detected in $1.8 \%$ of the women. In a previous study performed in Recife on women with normal cytology (28), it was observed that $78.6 \%$ of HPV PCR-positive women were infected by genotypes of high-risk HPV, with HPV 16 being the most prevalent with $7.0 \%$, followed by HPV 31 with $4.2 \%$ and HPV 58 with $1.4 \%$. The HPV 16 prevalence found in the present study was almost equal to the estimate by Clifford et al (27) for South America (15.0\%), but for HPV 58, 18 and 56, the prevalence rates were below those estimates for South America in the above-mentioned study.

The overall HPV prevalence in the women with cervical cancer was $85.4 \%$, similar to that reported by Eluf-Neto et al (23) in the southeastern region (84.0\%) and higher than that observed by Rabelo-Santos et al (1) in the Central region of Brazil (76.0\%). Among the patients in this study who were HPV PCR-positive, 92.6\% were infected by at least one high-risk HPV genotype. Considering single infection and association with other genotypes, HPV 16 was the most prevalent genotype, detected in $58.3 \%$ of the cases, followed by HPV 58 in $12.5 \%$ and HPV 18 in $8.3 \%$, and then by HPV 33 and HPV 45 , each detected in $4.2 \%$ of the samples. A previous study conducted in Recife, also in the northeastern region, by Lorenzato et al (28) found HPV 16, 31, 58, 33 and 18 with prevalence rates of 59.3, 11.9, 3.4, 5.1 and 5.1\%, respectively, in women with cervical cancer. Furthermore, the HPV 16 prevalence reported by Rabelo-Santos et al (1) in women with cervical cancer in the North, South and Southeast regions of Brazil, were 43.5, 52.2 and 53.8\%, respectively, below the value reported for the Northeast region. These results suggest that the women from Northeast Brazil may be more exposed to infection with high-risk HPV genotypes, particularly HPV 16, compared with those of other regions of the country. Based on these results, we believe that a vaccine capable of preventing HPV 16 and 18 may have a great impact on the burden of HPV-associated diseases in different geographic regions of Brazil, mainly the northeastern region.

\section{Acknowledgements}

The authors would like to thank CNPq and CAPES for their financial support and the Ludwig Institute for Cancer Research São Paulo Branch, for its technical support. 


\section{References}

1. Rabelo-Santos SH, Zeferino L, Villa LL, Sobrinho JP, Amaral RG and Magalhães AV: Human papillomavirus prevalence among women with cervical intraepithelial neoplasia III and invasive cervical cancer from Goiânia, Brazil. Mem Inst Oswaldo Cruz 98: 181-184, 2003.

2. Villa LL: Vaccine against papillomavirus infections and disease. Salud Publica Mex 45: S443-S448, 2003.

3. Trottier H and Franco EL: The epidemiology of genital human papillomavirus infection. Vaccine 24: S1-S15, 2006.

4. Muñoz N, Castellsagué X, De González AM and Gissmann L: Chapter 1: HPV in the etiology of human cancer. Vaccine 24 (Suppl 3): S1-S10, 2006.

5. Herrero R, Castle PE, Schiffman M, et al: Epidemiologic profile of type-specific human papillomavirus infection and cervical neoplasmia in Guanacaste, Costa Rica. J Infect Dis 191: 1796-1807, 2005.

6. Smith JS, Melendy A, Rana RK and Pimenta JM: Age-specific prevalence of infection with human papillomavirus in females: a global review. J Adolesc Health 43 (Suppl 4): S5-S25, 2008.

7. Chan PK, Chang AR, Yu MY, et al: Age distribution of human papillomavirus infection and cervical neoplasia reflects caveats of cervical screening policies. Int J Cancer 126: 297-301, 2010.

8. Snijders PJ, Steenbergen RD, Heideman DA and Meijer CJ: HPV-mediated cervical carcinogenesis: concepts and clinical implications. J Pathol 208: 152-164, 2006.

9. Moscicki AB, Schiffman M, Kjaer S and Villa LL: Chapter 5: Updating the natural history of HPV and anogenital cancer. Vaccine 24 (Suppl 3): S42-S51, 2006.

10. Sichero L, Ferreira S, Trottier H, et al: High grade cervical lesions are caused preferentially by non-european variants of HPVs 16 and 18. Int J Cancer 120: 1763-1768, 2007.

11. Almonte M, Albero G, Molano M, Carcamo C, García PJ and Pérez G: Risk factors for human papillomavirus exposure and co-factors for cervical cancer in Latin America and the Caribean. Vaccine 26 (Suppl 11): L16-L36, 2008.

12. Sherman ME, Schiffman MH, Erozan YS, Wacholder S and Kurman RJ: The Bethesda system. A proposal for reporting abnormal cervical smears based on the reproducibility of cytopathologic diagnoses. Arch Pathol Lab Med 116: 1155-1158, 1992.

13. Sambrook J and Russel DW: Molecular cloning: A Laboratory Manual. 3rd edition. Cold Spring Harbor Laboratory Press, New York, NY, 2001.

14. Saiki RK, Scharf S, Faloona F, et al: Enzymatic amplification of beta-globin genomic sequences and restriction site analysis for diagnosis of sickle cell anemia. Science 230: 1350-1354, 1985.

15. Manos MM, Ting T, Wright DK, Lewis AJ, Broker TR and Wolinsky SM: The use of polymerase chain reaction amplification for the detection of genital human papillomavirus. Cancer Cell Mol Diag Human Cancer 7: 209-214, 1989.
16. Sanguinetti CJ, Dias-Neto E and Simpson AJ: Rapid silver staining and recovery of PCR products separated on polyacrylamide gels. Biotechniques 17: 915-919, 1994.

17. Jacobs MV, De Roda Husman AM, van den Brule AJ, Snijders PJ, Meijer CJ and Walboomers JM: Group-specific differentiation between high- and low-risk human papillomavirus genotypes by general primer-mediated PCR and two cocktails of oligonucleotide probes. J Clin Microbiol 33: 901-905, 1995.

18. Schiffman M, Castle PE, Jeronimo J, Rodriguez AC and Wacholder S: Human papillomavirus and cervical cancer. Lancet 370: 890-907, 2007.

19. Weaver BA: Epidemiology and natural history of genital human papillomavirus infection. J Am Osteopath Assoc 106 (Suppl 1): S2-S8, 2006.

20. Ault KA: Human papillomavirus vaccines and the potential for cross-proctetion between related HPV types. Gynecol Oncol 107: S31-S33, 2007.

21. CDC- Centers for Disease Control and Prevention, Department of Health and Human Services: Prevention of genital human papillomavirus infection. http://www.cdc.gov/hpv/. Accessed May 09, 2011.

22. Bosch FX, Manos MM, Muñoz N, et al: Prevalence of human papillomavirus in cervical cancer: a worldwide perspective. J Nat Cancer Inst 87: 796-802, 1995.

23. Eluf-Neto J, Booth M, Muñoz N, Bosch FX, Meijer CJLM and Wallboomers JM: Human papillomavirus and invasive cervical cancer in Brazil. Br J Cancer 69: 114-119, 1994.

24. Noronha V, Mello W, Villa LL, et al: Papilomavírus humano associado a lesões de cérvice uterina. Rev Soc Bras Med Trop 32: 235-240, 1999.

25. Louie KS, De Sanjose S, Diaz M, et al: Early age at first sexual intercourse and early pregnancy are risk factors for cervical cancer in developing countries. Br J Cancer 100: 1191-1197, 2009.

26. Schoell WMJ, Janicek MFR and Mirhashemi R: Epidemiology and biology of cervical cancer. Semin Surg Oncol 16: 203-211, 1999.

27. Clifford GM, Gallus S, Herrero R, et al: Worldwide distribution of human papillomavius types in cytologically normal women in the International Agency for Research on Cancer HPV prevalence surveys: a pooled analysis. Lancet 366: 991-998, 2005.

28. Lorenzato F, Ho L, Terry G, et al: The use of human papillomavirus typing in detection of cervical neoplasia in Recife (Brazil). Int J Gynecol Cancer 10: 143-150, 2000.

29. Nonnenmacher B, Breitenbach V, Villa LL, Prolla JC and Bozzetti MC: Identificação do papilomavirus humano por biologia molecular em mulheres assintomáticas. Rev Saude Publica 36: 95-100, 2002. 